\title{
Determinan Rendahnya Partisipasi dalam Program Pengelolaan Penyakit Kronis di Puskesmas
}

\author{
Rizki Fadila ${ }^{1}$ dan Aisyah Nurmaliza Ahmad² \\ 1,2Health Insurance Program, Poltekkes Kemenkes Malang \\ rizkifadila@yahoo.com ${ }^{1}$
}

\begin{abstract}
ABSTRAK
Diajukan 3 Juni 2021 Diperbaiki 8 Agustus 2021 Diterima 13 Agustus 2021
\end{abstract}

Latar Belakang: Program pengelolaan penyakit kronis (Prolanis) diselenggarakan pemerintah sebagai wujud pengelolaan jangka panjang pada penyakit diabetes melitus dan hipertensi. Meskipun demikian, partisipasi pasien diabetes melitus dan hipertensi dalam kegiatan Prolanis di Puskesmas Kota Malang masih tergolong rendah. Hal tersebut menyebabkan belum dapat terpenuhinya target indikator Rasio Peserta Prolanis Terkendali (RPPT) pada beberapa Puskesmas di Kota Malang.

Tujuan: Menganalisis faktor yang mempengaruhi partisipasi dalam Program Pengelolaan Penyakit Kronis (Prolanis).

Metode: Jenis penelitian ini adalah observasional dengan pendekatan cross-sectional. Sebanyak 85 peserta prolanis yang terdaftar di Puskesmas Kendalkerep Kota Malang dipilih menjadi sampel dengan teknik total sampling. Instrumen yang digunakan adalah kuesioner. Data dianalisis dengan menggunakan uji chisquare dan regresi logistik.

Hasil: Peserta yang tidak berpartisipasi aktif dalam Prolanis sebanyak 70,6\%. Hasil uji chi square menunjukkan bahwa tingkat pengetahuan $(p=0,000)$, persepsi keseriusan penyakit $(p=0,000)$ dan dukungan keluarga $(\mathrm{p}=0,010)$ berhubungan dengan rendahnya partisipasi Prolanis. Uji regresi logistik menunjukkan tingkat pengetahuan memiliki nilai $\mathrm{OR}=37,410(3,950-354,286)$ dan persepsi keseriusan penyakit memiliki nilai OR $=70,544(8,182-608,238)$.

Kesimpulan: Faktor yang paling mempengaruhi partisipasiprolanis adalah tingkat pengetahuan dan persepsi keseriusan penyakit.

Kata Kunci: pengetahuan; persepsi keseriusan; dukungan keluarga; partisipasi; prolanis

\section{ABSTRACT}

Background: The chronic disease management program (Prolanis) is held by the government as a form of longterm management of diabetes mellitus and hypertension. Even so, the participation of diabetes mellitus and hypertension patients in Prolanis activities at Malang City Health Center is still low. This has failed to fulfill the target indicator for the Controlled Prolanis Participant Ratio (RPPT) at several Puskesmas in Malang City.

Objective: To analyze the factors that influence participation in the Chronic Disease Management Program (Prolanis).

Methods: The research design used was observational with a cross-sectional approach. A total of 85 Prolanis participants registered at the Kendalkerep Public Health Center Malang City were selected as samples with a total sampling technique. The instrument used was a questionnaire. Data were analyzed using the chi square test and logistic regression.

Results: Participants who did not actively participate in Prolanis were $70.6 \%$. The results of the chi square test showed that the level of knowledge $(p=0.000)$, the perceived seriousness of the disease $(p=0.000)$, and family support $(p=0.010)$ were associated with low Prolanis participation. The logistic regression test showed the level of knowledge had an OR value of $37,410(3,950-354,286)$ and the perceived seriousness of the disease had an OR value of $70.544(8,182-608,238)$.

Conclusion: The factors that most influence Prolanis participation are the level of knowledge and the perceived seriousness of the disease.

Keywords: knowledge; perceived of severity; family support; participation; prolanis 
PENDAHULUAN

Penyakit Tidak Menular (PTM) bertanggung jawab terhadap sedikitnya $70 \%$ kematian di Indonesia. Hasil Riset Kesehatan Dasar 2018 menunjukkan adanya peningkatan prevalensi PTM seperti hipertensi dari $25.8 \%$ menjadi $34.1 \%$, diabetes melitus dari $6.9 \%$ menjadi $8,5 \%$, stroke dari $7 \%$ o menjadi $10.9 \%$, penyakit ginjal kronis dari $2 \%$ menjadi $3.8 \%$ dan kanker dari $1.4 \%$ menjadi $1.8 \%$ (Balitbangkes, 2018). Berdasarkan data tersebut dapat disimpulkan bahwa penyakit hipertensi dan diabetes melitus adalah dua penyakit kronis dengan prevalensi tertinggi di Indonesia.

Hipertensi (HT) dan diabetes melitus (DM) membutuhkan pembiayaan yang relatif mahal jika tidak dikelola dengan baik (Susyanty dan Pujiyanto, 2013). Oleh karena itu, hipertensi dan diabetes melitus membutuhkan pengelolaan jangka panjang agar tidak menimbulkan komplikasi terhadap berbagai macam penyakit, seperti penyakit jantung, stroke, serta retinopati (Long \& Dagogo-Jack, 2011; Yulsam et al., 2015). Pasien diabetes melitus dan hipertensi juga dapat mengalami depresi, kecemasan, maupun gangguan psikososial lainnya (Gore et al., 2005) sehingga berimplikasi pada rendahnya kualitas hidup pasien (Papazafiropoulou et al., 2015).

Berbagai macam upaya telah dilakukan pemerintah untuk menekan peningkatan jumlah penderita penyakit kronis. Salah satu upaya tersebut melalui penyelenggaraan program pengelolaan penyakit kronis (Prolanis) dengan tujuan untuk memelihara kesehatan penderita penyakit kronis agar tercapai taraf hidup yang lebih optimal. Prolanis melibatkan peserta, fasilitas kesehatan dan BPJS Kesehatan melalui kegiatan konsultasi medis maupun edukasi, kunjungan rumah, aktivitas klub dan pemantauan status kesehatan (BPJS Kesehatan, 2014).

Partisipasi pasien diabetes melitus dan hipertensi dalam Prolanis terbukti dapat meningkatkan kualitas hidup (Wicaksono \& Fajriyah, 2018). Pasien penyakit kronis yang mendapatkan edukasi dan konseling menunjukkan kadar gula darah puasa (GDP) dan gula darah post prandial (GDPP) yang memenuhi target (Nugraheni et al., 2015). Selain itu, peserta yang aktif mengikuti kegiatan Prolanis terbukti dapat menurunkan kadar gula darah (Patima et al., 2019) dan menurunkan tekanan darah pada penderita hipertensi (Lumempouw et al, 2016; Syamson et al., 2020).

Meskipun Prolanis terbukti dapat memperbaiki kualitas hidup pesertanya, tetapi berdasarkan data monitoring evaluasi BPJS Kesehatan Kantor Cabang Malang di 15 puskesmas Kota Malang selama bulan Januari hingga Desember 2019 masih terdapat beberapa puskesmas dengan partisipasi Prolanis yang rendah. Hal tersebut dibuktikan dengan tidak terpenuhinya indikator Rasio Peserta Prolanis Terkendali (RPPT) sesuai dengan ketentuan Peraturan BPJS No. 7 Tahun 2019. Rata-rata hanya 53\% Puskesmas di Kota Malang yang mampu memenuhi target indikator RPPT minimal 5\%.

Dalam hal ini, indikator RPPT bertujuan untuk mengetahui optimalisasi penatalaksanaan Prolanis oleh FKTP. Apabila target indikator RPPT tidak mencapai target yang ditetapkan, maka akan berimplikasi terhadap penyesuaian terhadap pembayaran kapitasi kepada puskesmas (BPJS Kesehatan, 2019).

Puskesmas Kendalkerep sebagai salah satu penyelenggara Prolanis di Kota Malang memiliki jumlah peserta JKN terdaftar pada bulan Oktober 2020 sebanyak 32.172 jiwa serta terdapat 605 pasien dengan diagnosa diabetes melitus dan sebanyak 1.890 pasien dengan diagnosa hipertensi. Puskesmas Kendalkerep merupakan salah satu Puskesmas di Kota Malang yang belum dapat memenuhi target indikator RPPT.

Adapun rata-rata capaian indikator RPPT Puskesmas Kendalkerep hanya 
sebesar $0,92 \%$ sehingga mendapatkan kriteria rating 1 karena capaian indikator RPPT kurang dari 3\% (BPJS Kesehatan, 2019). Berdasarkan data tersebut dapat disimpulkan bahwa partisipasi peserta dalam kegiatan Prolanis di Puskesmas Kendalkerep masih rendah. Dengan kata lain, masih banyak peserta Prolanis yang belum memanfaatkan pelayanan yang disediakan oleh Puskesmas Kendalkerep Kota Malang.

Partisipasi peserta Prolanis akan mempengaruhi besaran kapitasi yang diterima oleh pemberi pelayanan kesehatan. Selain itu, kondisi kesehatan pasien tidak dapat terpantau dengan baik apabila tidak rutin berkunjung. Oleh karena itu, tujuan penelitian ini adalah untuk menganalisis determinan rendahnya partisipasi dalam Program Pengelolaan Penyakit Kronis di Puskesmas.

\section{METODE}

Penelitian ini merupakan penelitian observasional dengan menggunakan pendekatan Cross Sectional. Adapun variabel bebas dalam penelitian terdiri dari usia, jenis kelamin, tingkat pendidikan, status pekerjaan, tingkat pengetahuan, dukungan keluarga, aksesibilitas serta persepsi keseriusan penyakit. Variabel terikat pada penelitian ini yaitu partisipasi program pengelolaan penyakit kronis (Prolanis).

Variabel persepsi keseriusan penyakit merupakan penilaian peserta terkait keseriusan penyakit yang dialami. Dalam hal ini responden menganggap penyakitnya akan semakin rentan terjadi komplikasi serta kadar gula darah penderita DM dan tekanan darah penderita HT tidak akan terkontrol jika tidak mengikuti kegiatan Prolanis. Kuesioner berisi 8 pertanyaan, $\mathrm{t}$ kemudian dikategorikan menjadi persepsi positif dan negatif.

Tingkat pengetahuan merupakan pemahaman responden tentang Prolanis yang diukur dengan memberikan 15 pertanyaan meliputi pengertian Prolanis, tujuan Prolanis, syarat menjadi peserta Prolanis, jadwal dan jenis kegiatan Prolanis serta penyakit yang ditangani Prolanis. Selanjutnya variabel tingkat pengetahuan dikategorikan menjadi tinggi dan rendah.

Aksesibilitas merupakan kemudahan responden datang ke Puskesmas untuk mengikuti kegiatan Prolanis yang diukur berdasarkan jarak, waktu tempuh, ketersediaan sarana transportasi, dan biaya yang dibutuhkan. Variabel aksesibilitas selanjutnya dikategorikan menjadi mudah dan sulit.

Partisipasi Prolanis merupakan tingkat keaktifan peserta untuk mengikuti kegiatan Prolanis secara rutin ke Puskesmas sesuai jadwal yang ditentukan. Partisipasi peserta Prolanis dapat dilihat dari absen atau daftar hadir peserta Prolanis selama 6 bulan terakhir. Dalam hal ini responden dikategorikan tidak berpartisipasi aktif jika frekuensi kedatangan $\leq 3$ kali, sedangkan responden dikategorikan berpartisipasi aktif jika frekuensi kedatangan $>3$ kali.

Waktu pelaksanaan penelitian adalah bulan September - November 2020 di Puskesmas Kendalkerep Kota Malang. Sampel diperoleh dengan menggunakan teknik total sampling. Sebanyak 85 peserta Prolanis di Puskesmas Kendalkerep dipilih untuk menjadi sampel. Pemilihan Puskesmas Kendalkerep didasarkan karena memiliki capaian rasio peserta Prolanis terendah di Kota Malang sehingga diharapkan dapat mewakili Puskesmas lainnya yang juga melaksanakan Prolanis.

Data dalam penelitian ini diambil dengan menggunakan angket kuesioner yang berisikan nama, alamat, umur, pendidikan terakhir, status pekerjaan, tingkat pengetahuan, dukungan keluarga, aksesibilitas, dan persepsi keseriusan penyakit peserta Prolanis. Data primer didapatkan dari hasil kuesioner, 
Determinan Rendahnya Partisipasi dalam Program Pengelolaan Penyakit...

sedangkan data sekunder merupakan dokumentasi data dari Puskesmas Kendalkerep.

Setelah data dikumpulkan, selanjutnya ditampilkan dalam bentuk tabel dan diinterpretasikan dalam narasi serta dilakukan analisis menggunakan uji univariat, bivariat dan multivariat. Analisis bivariat menggunakan uji chi square, sedangkan analisis multivariat menggunakan uji Regresi Logistik.

\section{HASIL DAN PEMBAHASAN}

Tabel 1 menyajikan hasil analisis univariat yang diperoleh dari 85 responden. Berdasarkan data tersebut, sebagian besar responden termasuk dalam kategori lansia. Mayoritas responden berjeniskelamin perempuan dengan status pekerjaan adalah tidak bekerja. Sebagian besar responden memiliki tingkat pendidikan menengah serta memiliki tingkat pengetahuan rendah. Mayoritas responden memiliki persepsi negatif tentang keseriusan penyakit. Selain itu, sebagian besar responden tidak mendapatkan dukungan keluarga dan mayoritas responden memiliki aksesibilitas yang mudah.

Tabel 1. Karakteristik Responden Peserta Prolanis di Puskesmas Kendalkerep Malang

\begin{tabular}{|c|c|c|c|}
\hline No. & Karakteristik & $\begin{array}{c}\text { Jumlah } \\
(\mathrm{n}=85)\end{array}$ & $\begin{array}{c}\text { Persen } \\
\text { tase }\end{array}$ \\
\hline \multirow[t]{3}{*}{1} & Usia & & \\
\hline & Pra-Lansia & 25 & 29,4 \\
\hline & Lansia & 60 & 70,6 \\
\hline \multirow[t]{3}{*}{2} & Jenis Kelamin & & \\
\hline & Laki-laki & 20 & 23,5 \\
\hline & Perempuan & 65 & 76,5 \\
\hline \multirow[t]{3}{*}{3} & Pekerjaan & & \\
\hline & Bekerja & 23 & 27,1 \\
\hline & Tidak Bekerja & 62 & 72,9 \\
\hline
\end{tabular}

\begin{tabular}{|c|c|c|c|}
\hline \multicolumn{4}{|c|}{ Pendidikan } \\
\hline & Rendah & 32 & 37,6 \\
\hline & Menengah & 40 & 47,1 \\
\hline & Tinggi & 13 & 15,3 \\
\hline \multirow[t]{3}{*}{5} & Pengetahuan & & \\
\hline & Tinggi & 22 & 25,9 \\
\hline & Rendah & 63 & 74,1 \\
\hline \multirow[t]{3}{*}{6} & Persepsi Keseriusan & & \\
\hline & Positif & 29 & 34,1 \\
\hline & Negatif & 56 & 65,9 \\
\hline \multirow[t]{3}{*}{7} & Dukungan Keluarga & & \\
\hline & Mendukung & 27 & 31,7 \\
\hline & Tidak Mendukung & 58 & 68,3 \\
\hline \multirow[t]{3}{*}{8} & Aksesibilitas & & \\
\hline & Mudah & 74 & 87,1 \\
\hline & Sulit & 11 & 12,9 \\
\hline
\end{tabular}

Tabel 2 menunjukkan analisis bivariat terhadap partisipasi peserta Prolanis. Hasil uji chi square berdasarkan Tabel 2 menunjukkan bahwa tidak terdapat hubungan antara usia dengan partisipasi Prolanis $\quad(p=0,057)$, tidak terdapat hubungan antara jenis kelamin dengan partisipasi Prolanis $(p=0,291)$, tidak terdapat hubungan antara pekerjaan dengan partisipasi Prolanis $(p=0,900)$, tidak terdapat hubungan antara pendidikan dengan partisipasi Prolanis $(p=0,239)$, dan tidak terdapat hubungan antara aksesibilitas dengan partisipasi Prolanis $(p=0,588)$.

Namun, ada pula beberapa variabel yang berpengaruh pada partisipasi peserta. Berdasarkan hasil analisis chi square pada Tabel 2 tersebut, diketahui bahwa terdapat hubungan pengetahuan peserta dengan partisipasi Prolanis $(p=$ $0,000)$, terdapat hubungan antara persepsi keseriusan penyakit dengan partisipasi Prolanis $(p=0,000)$ dan terdapat hubungan antara dukungan keluarga dengan partisipasi Prolanis $(\mathrm{p}=0,010)$.

Tabel 2. Analisis Bivariat Partisipasi Dalam Prolanis Di Puskesmas

\begin{tabular}{|c|c|c|c|c|c|}
\hline \multirow[b]{2}{*}{ No. } & \multirow[b]{2}{*}{ Variabel } & \multirow[b]{2}{*}{ Katergori } & \multicolumn{2}{|c|}{ Partisipasi dalam Prolanis } & \multirow[b]{2}{*}{$P$ value } \\
\hline & & & $\begin{array}{c}\text { Tidak } \\
\text { Berpartisipasi }\end{array}$ & Berpartisipasi & \\
\hline \multirow[t]{2}{*}{1} & Usia & Pra Lansia & 14 & 11 & 0,057 \\
\hline & & Lansia & 46 & 14 & \\
\hline \multirow[t]{2}{*}{2} & Jenis Kelamin & Laki-laki & 16 & 4 & 0,291 \\
\hline & & Perempunaan & 44 & 21 & \\
\hline
\end{tabular}


Determinan Rendahnya Partisipasi dalam Program Pengelolaan Penyakit...

\begin{tabular}{|c|c|c|c|c|c|}
\hline \multirow[t]{2}{*}{3} & Pekerjaan & Rendah & 16 & 7 & 0,900 \\
\hline & & Menegah & 44 & 18 & \\
\hline \multirow[t]{3}{*}{4} & Pendidikan & Tinggi & 26 & 6 & 0,239 \\
\hline & & Tinggi & 26 & 14 & \\
\hline & & Rendah & 8 & 5 & \\
\hline \multirow[t]{2}{*}{5} & Pengetahuan & Positif & 1 & 11 & 0,000 \\
\hline & & Negatif & 60 & 13 & \\
\hline \multirow[t]{2}{*}{6} & Perepsi Keseriusan & Mendukung & 8 & 21 & 0,000 \\
\hline & & Tidak Mendukung & 52 & 4 & \\
\hline \multirow[t]{2}{*}{7} & Dukungan Keluarga & Mudah & 14 & 13 & 0,010 \\
\hline & & Sulit & 46 & 12 & \\
\hline \multirow[t]{2}{*}{8} & Aksesibilias & & 53 & 21 & 0,588 \\
\hline & & & 7 & 4 & \\
\hline
\end{tabular}

Hasil uji regresi logistik pada Tabel 3 menunjukkan bahwa variabel yang secara signifikan mempengaruhi rendahnya partisipasi peserta dalam mengikuti kegiatan Prolanis adalah tingkat pengetahuan dan persepsi keseriusan penyakit. Dalam hal ini, peserta dengan pengetahuan rendah 37,410 kali lebih mungkin untuk tidak berpartisipasi aktif dalam Prolanis jika dibandingkan dengan peserta yang memiliki tingkat pengetahuan yang tinggi. Selain itu, peserta yang memiliki persepsi keseriusan negatif 70,544 kali lebih mungkin untuk tidak berpartisipasi aktif dalam Prolanis jika dibandingkan dengan peserta yang memiliki persepsi keseriusan positif.

\section{PEMBAHASAN}

\section{Hubungan Tingkat Pengetahuan dengan Partisipasi Program Pengelolaan Penyakit Kronis}

Pengetahuan memiliki peran penting dalam menentukan perilaku dan penerimaan suatu inovasi oleh seseorang. Selain dari pendidikan formal, tingkat pengetahuan ditentukan berdasarkan faktor sosial ekonomi, pengalaman, serta informasi yang didapatkan oleh seseorang (Puspita \& Rakhma, 2018). Dalam hal ini, pengetahuan yang diperoleh akan memberikan motivasi dan kesadaran untuk berpartisipasi aktif dalam Prolanis di puskesmas (S. M. Purnamasari \& Prameswari, 2020).

Fakta di lapangan menunjukkan bahwa sebagian besar responden belum mengetahui manfaat yang akan didapatkan jika peserta aktif berpartisipasi dalam Prolanis. Selain itu, responden juga belum memahami dengan baik jenis kegiatan yang dilaksanakan dalam Prolanis. Hal ini disebabkan karena peserta tidak aktif dalam mengikuti edukasi Prolanis yang diberikan oleh Puskesmas.

Berdasarkan hasil analisis variabel tingkat pengetahuan, diperoleh $p$ value < 0,05 sehingga dapat ditarik kesimpulan bahwa terdapat hubungan antara tingkat pengetahuan dengan partisipasi dalam Prolanis. Hasil penelitian ini sejalan dengan (Asfiani \& Ilyas, 2017; Ginting et al., 2020; S. M. Purnamasari \& Prameswari, 2020) yang menyatakan bahwa partisipasi masyarakat dalam Prolanis dipengaruhi oleh tingkat pengetahuan.

Pengetahuan berperan penting untuk mendukung partisipasi peserta dalam Prolanis. Pengetahuan yang baik tentang penyakit diabetes melitus dikaitkan puladengan baiknya manajemen perawatan diri, termasuk partisipasi dalam program edukasi diabetes (Adejoh, 2014; Haas et al., 2014).

Hubungan antara pengetahuan dan partisipasi dalam program edukasi diabetes juga berlangsung dalam dua arah. Partisipasi yang baik dalam mengikuti Prolanis dapat meningkatkan pengetahuan dan manajemen perawatan diri pasien diabetes melitus (Asfiani \& Ilyas, 2017). Pengetahuan yang baik tentang Prolanis diharapkan dapat memberikan kesadaran untuk berpartisipasi aktif dalam kegiatan. 
Determinan Rendahnya Partisipasi dalam Program Pengelolaan Penyakit...

Tabel 3. Analisis Multivariat Partisipasi Dalam Prolanis Di Puskesmas

\begin{tabular}{lccccc}
\hline No. & Variabel & Sig. & OR & \multicolumn{2}{c}{ 95\% C.I. for OR } \\
\cline { 5 - 7 } & & & Lower & Upper \\
\hline 1 & Pengetahuan & 0,002 & 37,410 & 3,950 & 354,286 \\
2 & Perepsi Keseriusan & 0,000 & 70,544 & 8,182 & 608,238 \\
3 & Dukungan & 0,299 & 2,466 & 0,449 & 13,530 \\
\hline
\end{tabular}

Hubungan Persepsi Keseriusan dengan Partisipasi Program Pengelolaan Penyakit Kronis

Teori Health Belief Model (HBM) digunakan untuk mengevaluasi tingkat partisipasi masyarakat atau individu dalam mengikuti suatu program kesehatan. Salah satu faktor untuk mengevaluasi partisipasi tersebut dapat dilihat dari faktor persepsi. Teori HBM membahas secara rinci tentang persepsi kerentanan (susceptibility), persepsi keseriusan (severity), persepsi manfaat (benefit), persepsi hambatan (barrier), dukungan melakukan tindakan (cues toaction) dan keyakinan akan kemampuan untuk melakukan tindakan yang direkomendasikan (self-efficacy) (Glanz et al., 2008).

Adapun persepsi yang digunakan dalam penelitian ini adalah persepsi keseriusan penyakit. Elemen yang untuk mengukur variabel persepsi keseriusan penyakit terdiri dari sikap, minat, pengalaman dan harapan terkait Prolanis.

Persepsi keseriusan dapat mempengaruhi pengambilan keputusan seseorang dalam bertindak. Jika seseorang menilai bahwa penyakit yang diderita serius, upaya seseorang untuk mengobati penyakit tersebut akan semakin tinggi (Ariana et al., 2020). Apabila hal ini dikaitkan dengan Prolanis, dapat dikatakan bahwa seseorang akan merasa penyakit yang diderita semakin serius saat tidak berpartisipasi aktif dalam kegiatan Prolanis.

Berdasarkan hasil analisis variabel persepsi keseriusan penyakit, diperoleh nilai $p$ value $<0,05$ sehingga dapat ditarik kesimpulan bahwa terdapat hubungan antara persepsi keseriusan penyakit dengan partisipasi dalam Prolanis. Sejalan dengan hal tersebut, Asfiani \& Ilyas, (2017) dan Purnamasari (2017) menyatakan bahwa partisipasi masyarakat dalam Prolanis dipengaruhi oleh persepsi keseriusan penyakit.

Hasil penelitian ini juga sejalan dengan teori Health Belief Model yang menyatakan bahwa persepsi, dalam hal ini keseriusan, dapat memberikan pengaruh pada keputusan seseorang untuk melakukan suatu tindakan, mengobati serta mengurangi resiko semakin menurunnya kondisi kesehatan seseorang. Seorang individu akan mengambil tindakan untuk melindungi diri jika mereka menganggap bahwa kondisi kesehatannya dalam masalah yang serius.

Persepsi keseriusan terhadap penyakit akan sangat bermanfaat bagi pasien penderita diabetes melitus dan hipertensi. Dalam hal ini, jika pasien mengetahui bahwa mereka beresiko terkena komplikasi penyakit lain akibat penyakit diabetes melitus dan hipertensi yang diderita, mereka dapat segera mengambil tindakan pencegahan penyakit seperti mengikuti sebuah program kesehatan (Edelman et al, 2013).

Apabila hal tersebut dikaitkan dengan Prolanis, adanya persepsi keseriusan terhadap penyakit diabetes dan hipertensi dalam diri seseorang, menjadikan peserta berpartisipasi aktif untuk mengikuti Prolanis. Hal ini disebabkan karena seseorang harus melakukan upaya untuk mencegah terjadinya komplikasi penyakit yang lebih parah. Tindakan tersebut biasanya akan muncul apabila seseorang sudah memiliki persepsi adanya keseriusan terhadap suatu penyakit (Ariana et al., 2020). 
Hubungan Dukungan Keluarga dengan Partisipasi Program Pengelolaan Penyakit Kronis

Dukungan keluarga merupakan suatu bentuk interaksi antar individu untuk memberikan rasa nyaman dalam bentuk fisik maupun psikis yang diwujudkan dengan pemenuhan kebutuhan terhadap kasih sayang dan rasa aman yang dapat diwujudkan dalam bentuk empati, dukungan, fasilitatif dan partisipatif (Hensarling, 2009). Berdasarkan hasil analisis uji Chi Square didapatkan nilai $p$ value $=0,010$ sehingga mengindikasikan bahwa terdapat hubungan antara dukungan keluarga dengan partisipasi dalam kegiatan Prolanis.

Beberapa penelitian menyebutkan bahwa adanya dukungan keluarga yang baik pada penderita diabetes melitus tipe2 dan hipertensi akan meningkatkan motivasi untuk mengikuti kegiatan Prolanis (Harniati et al., 2019; Wildan et al., 2019). Dukungan keluarga memberikan potensi untuk meningkatkan manajemen diri penderita penyakit kronis dan menurunkan peluang terjadinya penyakit kronis yang sama pada anggota keluarga yang belum terdiagnosis (Ramal et al., 2012).

Selain itu, dukungan keluarga dapat bermanfaat bagi kesehatan pasien karena akanmengurangistres (Miller \& Dimatteo, 2013), mengendalikan rasa takut, meningkatkan efikasi diri, mengurangi perilaku kesehatan yang negatif (DiMatteo, 2004) dan dapat mengendalikan indeks glikemik pasien diabetes (Pamungkas et al., 2017). Dapat disimpulkan bahwa kesehatan seseorang sangat dipengaruhi oleh adanya dukungan dalam keluarga. Jika dukungan keluarga yang diberikan pada penderita diabetes melitus dan hipertensi makin besar, akan makin meningkatkan peluang dan keinginan seseorang untuk hidup sehat.

\section{Kesimpulan}

Berdasarkan hasil penelitian dapat disimpulkan bahwa terdapat hubungan antara pengetahuan, persepsi keseriusan, dan dukungan keluarga dengan rendahnya partisipasi peserta BPJS Kesehatan untuk mengikuti kegiatan Prolanis. Hasil analisis regresi logistik menunjukan bahwa faktor yang paling berhubungan dengan rendahnya partisipasi dalam kegiatan Prolanis adalah pengetahuan dan persepsi keseriusan.

\section{Saran}

Peserta Prolanis diharapkan berpartisipasi aktif dalam kegiatan Prolanis agar dapat meningkatkan kualitas hidup peserta. Selain itu, BPJS Kesehatan diharapkan agar meningkatkan monitoring dan evaluasi dalam pelaksanaan Prolanis di Puskesmas untuk memastikan pelaksanaan Prolanis sesuai dengan prosedur yang telah ditetapkan. Di sisi lain, diharapkan Puskesmas lebih aktif memberikan sosialisasi dan edukasi terkait Prolanis kepada peserta dan melaksanakan kegiatan pokok Prolanis secara rutin, yaitu edukasi, penyuluhan, reminder dan home visit.

\section{DAFTAR PUSTAKA}

Adejoh, S. O. (2014). Diabetes knowledge, health belief, and Diabetes management among the Igala, Nigeria. SAGE Open, 4(2). https:// doi.org/10.1177/2158244014539966

Ariana, R., Sari, C. W. M., \& Kurniawan, T. (2020). Perception of Prolanis Participants About Chronic Disease Management Program Activities (PROLANIS) in the Primary Health Service Universitas Padjadjaran. NurseLine Journal, 4(2), 103. https:// doi.org/10.19184/nlj.v4i2.12687

Asfiani, L. V., \& Ilyas, Y. (2017). Level of Adherence and Its Determinants of Prolanis Attendance in Type 2 Diabetes Mellitus Participants at Five BPJS Primary Health Care in Bekasi 
2016. Journal of Indonesian Health Policy and Administration, 2(2), 6. https:// doi.org/10.7454/ihpa.v2i2.1899

Balitbangkes. (2018). Laporan Nasional Riskesdas 2018.pdf. In Badan Penelitian dan Pengembangan Kesehatan (p. 198). http://labdata.litbang.kemkes.go.id/ images/download/laporan/RKD/2018/ Laporan_Nasional_RKD2018_FINAL. pdf

BPJS Kesehatan. (2014). Panduan Praktis PROLANIS (Program Pengelolaan Penyakit Kronis). In BPJS Kesehatan.

BPJS Kesehatan. (2019). Peraturan Badan Penyelenggara Jaminan Sosial Kesehatan Nomor 7 Tahun 2019 tentang Petunjuk Pelaksanaan Pembayaran Kapitasi Berbasis Kinerja. BPJS Kesehatan.

DiMatteo, M. R. (2004). Social support and patient adherence to medical treatment: a meta-analysis. Health Psychology: Official Journal of the Division of Health Psychology, American Psychological Association, 23(2), 207218. https://doi.org/10.1037/02786133.23.2.207

Edelman Carole, Kudzma Elizabeth, \& Carol, M. (2013). No Health Promotion Throughout the Life Span 8th EditionTitle. St. Louis (US): Mosby Elsevier.

Ginting, R., Hutagalung, P. G. J., Hartono, H., \& Manalu, P. (2020). Faktor-faktor yang mempengaruhi pemanfaatan Program Pengelolaan Penyakit Kronis (Prolanis) pada lansia di Puskesmas Darussalam Medan. Jurnal Prima Medika Sains, 2(2 SE-), 24-31. https:// doi.org/10.1616/jpms.v2i2.972

Glanz, K., Rimer, B. K., \& Viswanath, K. (2008). Health Behavior and Health Education: Theory, Research, and Practice. Wiley. https:// books.google.co.id/books? id=WsHxyj710UgC

Gore, M., Brandenburg, N. A., Dukes, E., Hoffman, D. L., Tai, K.-S., \& Stacey, B. (2005). Pain severity in diabetic peripheral neuropathy is associated with patient functioning, symptom levels of anxiety and depression, and sleep. Journal of Pain and Symptom Management, 30(4), 374-385. https:// doi.org/10.1016/

j.jpainsymman.2005.04.009

Haas, L., Maryniuk, M., Beck, J., Cox, C. E., Duker, P., Edwards, L., Fisher, E. B., Hanson, L., Kent, D., Kolb, L., McLaughlin, S., Orzeck, E., Piette, J. D., Rhinehart, A. S., Rothman, R., Sklaroff, S., Tomky, D., \& Youssef, G. (2014). National standards for Diabetes self-management education and support. Diabetes Care, 37 Suppl 1(Suppl 1), S144-53. https://doi.org/ 10.2337/dc14-S144

Harniati, A., Suriah, S., \& Amqam, H. (2019). Ketidakpatuhan Peserta BPJS Kesehatan Mengikuti Kegiatan Prolanis Di Puskesmas Rangas Kabupaten Mamuju. Jurnal Kesehatan Masyarakat Maritim, 1(1). https:// doi.org/10.30597/jkmm.v1i1.8689

Hensarling. (2009). Development and psychometric testing of HEnsarling's Diabetes family support scale, a dissertation. Degree of Doctor of Philosophi in the Graduate School of Texa's Women"s University.

Long, A. N., \& Dagogo-Jack, S. (2011). Comorbidities of Diabetes and Hypertension: Mechanisms and Approach to Target Organ Protection. Journal of Clinical Hypertension, 13(4), 244-251. https://doi.org/10.1111/j.17517176.2011.00434.x

Lumempouw, D. O., Wungouw, H. I. ., \& Polii, H. . (2016). Pengaruh senam Prolanis terhadap penyandang Hipertensi. Jurnal E-Biomedik, 4(1). https://doi.org/10.35790/ ebm.4.1.2016.11697

Miller, T. A., \& Dimatteo, M. R. (2013). Importance of family/social support and impact on adherence to diabetic therapy. Diabetes, Metabolic Syndrome and Obesity: Targets and Therapy, 6, 421426. https://doi.org/10.2147/ 
DMSO.S36368

Nugraheni, A. Y., Sari, I. P., \& Andayani, T. M. (2015). Pengaruh Konseling Apoteker Dengan Alat Bantu Pada Pasien Diabetes Melitus. Manajemen Dan Pelayanan Farmasi, 5(4), 233-240. https://doi.org/10.22146/jmpf.214

Pamungkas, R. A., Chamroonsawasdi, K., \& Vatanasomboon, P. (2017). A systematic review: Family support integrated with Diabetes selfmanagement among uncontrolled type II Diabetes mellitus patients. Behavioral Sciences, 7(3), 1-17. https:// doi.org/10.3390/bs7030062

Papazafiropoulou, A. K., Bakomitrou, F., Trikallinou, A., Ganotopoulou, A., Verras, C., Christofilidis, G., Bousboulas, S., \& Melidonis, A. (2015). Diabetes-dependent quality of life (ADDQOL) and affecting factors in patients with Diabetes mellitus type 2 in Greece. BMC Research Notes, 8, 786. https://doi.org/10.1186/s13104-0151782-8

Patima, N., Darwis, D., \& Hasanuddin, H. (2019). Pengaruh Senam Prolanis Terhadap Penurunan Kadar Gula Darah Penderita Diabetes Melitus Tipe 2 Pada Lansia Di Puskesmas Binuang, Polman. Jurnal Ilmiah Kesehatan Diagnosis, 14, 343-346. https://doi.org/10.35892/jikd.v14i4.287

Purnamasari, S. M., \& Prameswari, G. N. (2020). Pemanfaatan Program Pengelolaan Penyakit Kronis di Puskesmas. HIGEIA (Journal of Public Health Research and Development), 4(2), 256-266. https://doi.org/10.15294/ higeia.v4i2.33805

Purnamasari, V. D. (2017). Pengetahuan Dan Persepsi Peserta Prolanis Dalam Menjalani Pengobatan Di Puskesmas. Preventia: The Indonesian Journal of Public Health, 2(1), 18. https://doi.org/ 10.17977/um044v2i1p18-24

Puspita, F. A., \& Rakhma, L. R. (2018). Hubungan Lama Kepesertaan Prolanis dengan Tingkat Pengetahuan
Gizi dan Kepatuhan Diet Pasien Diabetes Mellitus di Puskesmas Gilingan Surakarta. Jurnal Dunia Gizi, 1(2), 101. https://doi.org/10.33085/ jdg.v1i2.3076

Ramal, E., Petersen, A. B., Ingram, K. M., \& Champlin, A. M. (2012). Factors that influence Diabetes self-management in Hispanics living in low socioeconomic neighborhoods in San Bernardino, California. Journal of Immigrant and Minority Health, 14(6), 1090-1096. https://doi.org/10.1007/ s10903-012-9601-y

Susyanty, A. L., \& Pujiyanto. (2013). Hubungan Obesitas Dan Penyakit Kronis Terhadap Pemanfaatan Pelayanan Kesehatan (Analisis Data Riskesdas Dan Susenas 2007). Jurnal Ekologi Kesehatan, 12(2 Jun), 95-105. https://doi.org/10.22435/ jek.v12i2Jun.3850.95-105

Syamson, M. M., Fitri, N., \& Hasrul, H. (2020). Pengaruh senam Prolanis terhadap penurunan tekanan darah pada penderita Hipertensi. Holistik Jurnal Kesehatan, 14(1), 74-81. https:// doi.org/10.33024/hjk.v14i1.2330

Wicaksono, S., \& Fajriyah, N. N. (2018). Hubungan Keaktifan dalam Klub Prolanis Terhadap Peningkatan Kualitas Hidup Diabetisi Tipe 2. Jurnal Ilmiah Kesehatan (JIK), XI(I), 273-286. https://journal.stikesmuh-pkj.ac.id/ index.php/jik/article/view/87/81

Wildan, A., Pulungan, R. M., \& Permatasari, P. (2019). Pemanfaatan Prolanis Di Fasilitas Kesehatan Tingkat Pertama Wilayah Kota Depok. Media Kesehatan Masyarakat Indonesia, 18(4), 127-134. https://doi.org/ 10.14710/mkmi.18.4.127-134

Yulsam, P. Y., Oenzil, F., \& Efrida, E. (2015). Insidens Riwayat Hipertensi dan Diabetes Melitus pada Pasien Penyakit Jantung Koroner di RS. Dr. M. Djamil Padang. Jurnal Kesehatan Andalas, 4(2), 535-539. https://doi.org/ 10.25077/jka.v4i2.295 